\title{
A tribute to the memory of Dr. Kenji Honda
}

\author{
Shunichi Hoshino, MD
}

(C) The Japanese Association for Thoracic Surgery 2011

Dr. Kenji Honda, a former professor of Fukushima Medical University, passed away on March 17, 2011.

Dr. Honda was born in Kakuta City, Miyagi Prefecture, on July 6, 1918. He graduated from the Tohoku University School of Medicine in 1941. Upon graduation, he joined the First Department of Surgery of the Tohoku University School of Medicine, and after undergoing training in thoracic cardiovascular surgery and gastroenterological surgery, he was promoted to the rank of assistant professor in the university's First Department of Surgery in 1949. In 1959, he was appointed as a professor in the First Department of Surgery of Fukushima Medical University. There, for the next 24 years until his retirement in 1983, he was engaged in education, research, and medical practice over a wide range of fields in surgery such as thoracic cardiovascular surgery, gastroenterological surgery, and pediatric surgery.

Dr. Honda organized many academic medical congresses while he was with the Fukushima Medical University. He invited a founder of cardiac surgery, Professor D. E. Harken (Harvard University), and a pioneer in heart transplant surgery, Professor N. E. Shumway, to the 26th Congress of the Japanese Association for Thoracic Surgery (1973). Subsequently, he arranged for the 13th Congress of the Japanese Society of Pediatric Surgery (1976), the 15th Congress of the Japanese Society of Gastroenterological Surgery (1980), and the 8th Congress of the Japanese Association for Acute

S. Hoshino $(\bowtie)$

Fukushima Daiichi Hospital, 16-2 Nariide, Kitasawamata,

Fukushima 960-8251, Japan

Tel. +24-557-5111; Fax +24-557-5064

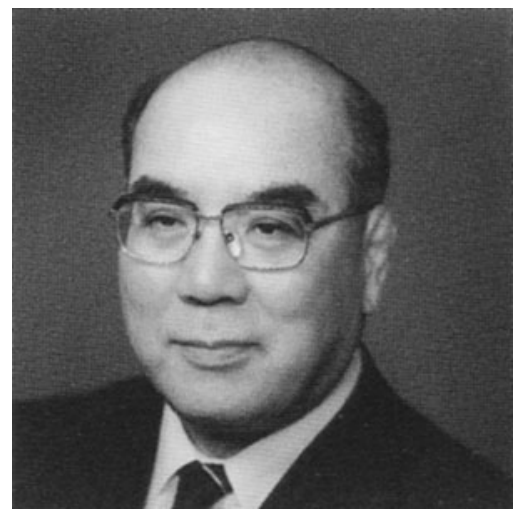

Medicine (1980) to be held in Fukushima City. In addition, he played an active role in international academic activities as the Chairman of the International College of Surgery (1983).

Dr. Honda participated actively in overseas cooperative medical activities while in office. From 1984, as the head of Japan Medical Team for Disaster Relief Committee, he led missions in countries such as Ethiopia, Mexico, and Colombia that had been struck by natural disasters (severe drought, major earthquake, volcanic eruptions), and demonstrated courage in personally going overseas for medical missions on several occasions.

Furthermore, in an effort to commemorate the life of Hideyo Noguchi, the Fukushima native who devoted his life to researching yellow fever and passed away in Ghana, Dr. Honda made a major contribution to the establishment of the Noguchi Memorial Institute of Medical Research at the University of Ghana in 1979.

We have the deepest respect for Dr. Kenji Honda's great achievements and pray for the repose of his soul. 